\title{
An Approach for Data Mining of Electronic Health Record Data for Suicide Risk Management: Database Analysis for Clinical Decision Support
}

Sofian Berrouiguet ${ }^{1,2,3,4}, \mathrm{MD}, \mathrm{PhD}$; Romain Billot ${ }^{4}, \mathrm{PhD}$; Mark Erik Larsen ${ }^{5}, \mathrm{PhD}$; Jorge Lopez-Castroman ${ }^{6}, \mathrm{MD}$, $\mathrm{PhD}$; Isabelle Jaussent ${ }^{7}, \mathrm{MD}, \mathrm{PhD}$; Michel Walter ${ }^{1}$, MD, PhD; Philippe Lenca ${ }^{4}$, PhD; Enrique Baca-García ${ }^{8,9,10,11,12,13,14}$, MD, PhD; Philippe Courtet ${ }^{7,10,11,15,16}, \mathrm{MD}, \mathrm{PhD}$

\footnotetext{
${ }^{1}$ Adult Psychiatry, Brest Medical University Hospital at Bohars, Brest, France

${ }^{2}$ EA 7479 Soins Primaires, Santé Publique, Registre des Cancers de Bretagne Occidentale, Université de Bretagne Occidentale, Brest, France

${ }^{3}$ Mental Health Department, University Hospital of Brest, Brest, France

${ }^{4}$ F-29238, Laboratoire des Sciences et Techniques de l'information de la Communication et de la Connaissance, IMT Atlantique, Brest, France

${ }^{5}$ Black Dog Institute, University of New South Wales, Sydney, Australia

${ }^{6}$ Inserm U1061, Crisis Admission Center, University Hospital of Nîmes, Nîmes, France

${ }^{7}$ Inserm U1061, La Colombières Hospital, University of Montpellier, Montpellier, France

${ }^{8}$ Carlos III Institute Of Health, Centro de Investigation en Salud Mental, Madrid, Spain

${ }^{9}$ Department of Psychiatry, Universitad Catolica del Maule, Talca, Chile

${ }^{10}$ Department of Psychiatry, General Hospital of Villaba, Madrid, Spain

${ }^{11}$ Department of Psychiatry, University Hospital Rey Juan Carlos, Mostoles, Spain

${ }^{12}$ Department of Psychiatry, University Hospital Infanta Elena, Valdemoro, Spain

${ }^{13}$ Psychiatry Department, Universidad Autónoma de Madrid, Madrid, Spain

${ }^{14}$ Department of Psychiatry, Instituto de Investigación Sanitaria de la Fundación Jiménez Díaz, Madrid, Spain

${ }^{15}$ Department of Emergency Psychiatry and Acute Care, Centre Hospitalier Universitaire de Montpellier, Université Montpellier, Montpellier, France

${ }^{16}$ Fondamental Foundation, Créteil, France
}

\section{Corresponding Author:}

Sofian Berrouiguet, MD, PhD

Adult Psychiatry

Brest Medical University Hospital at Bohars

Route de Ploudalmezeau

Brest, 29200

France

Phone: 33668204178

Email: sofian.berrouiguet@gmail.com

\section{Abstract}

Background: In an electronic health context, combining traditional structured clinical assessment methods and routine electronic health-based data capture may be a reliable method to build a dynamic clinical decision-support system (CDSS) for suicide prevention.

Objective: The aim of this study was to describe the data mining module of a Web-based CDSS and to identify suicide repetition risk in a sample of suicide attempters.

Methods: We analyzed a database of 2802 suicide attempters. Clustering methods were used to identify groups of similar patients, and regression trees were applied to estimate the number of suicide attempts among these patients.

Results: We identified 3 groups of patients using clustering methods. In addition, relevant risk factors explaining the number of suicide attempts were highlighted by regression trees.

Conclusions: Data mining techniques can help to identify different groups of patients at risk of suicide reattempt. The findings of this study can be combined with Web-based and smartphone-based data to improve dynamic decision making for clinicians. 
(JMIR Ment Health 2019;6(5):e9766) doi: 10.2196/mental.9766

\section{KEYWORDS}

clinical decision support system; data mining; electronic health; mobile phone; prevention; suicide; suicide attempts

\section{Introduction}

\section{Suicide Risk Assessment}

Over 800,000 people die of suicide every year, and it is estimated that for each suicide, there may have been $>20$ other attempted suicides. A previous attempt is the major predictor of death by suicide [1]. However, many other outcomes associated with suicidal behaviors should be considered in the preventive and therapeutic decision-making process for effective prevention [2]. Thus, clinical [3], environmental [4], and genetic [2] suicide risk factors have been intensively studied among suicide attempters. Indeed, attempters provide data to identify suicide-related risk factors, and such at-risk patients are a privileged target for proper prevention and intervention strategies (eg, by mitigating risk factors or by maintaining contact with clinical support) [5]. Empirically informed suicide risk assessment frameworks are useful in guiding the evaluation and treatment of individuals presenting with suicidal symptoms. Actual guidelines recommend the systematic identification of risk factors based on risk assessment scales [6]. Nevertheless, the limits of actual risk assessment procedures may be a false reassurance for clinicians, and the conflation of risk assessment and risk prediction may be confusing to clinicians [7]. Therefore, there is an urgent need for an innovative tool that could integrate both empirical and structured assessment to support decision making in suicide prevention.

\section{Clinical Decision-Support Systems}

Decision-support tools help providers in their decision-making process. The use of these tools has been on the rise in recent years owing to their ability to bring evidence-based medicine to the point of care. A clinical decision-support system (CDSS) is a health information system that is integrated into electronic health records (EHR), enabling easy and effective use by physicians [8]. The CDSS incorporates individual patient data, a rule engine, and a medical knowledge base to produce a patient-specific assessment or recommendation of a management plan [9]. The CDSS usually relies on the processing of clinical data gathered into EHRs. However, these techniques have been poorly explored in mental health and the suicide-prevention setting [10].

Thus, there is still an important need to develop a CDSS that supports clinician decision makers to choose, for example, the most appropriate treatment, the nature of a psychosocial strategy, or the duration of treatment in suicide prevention strategies. A key feature of such a CDSS is to identify a patient's risk in terms of a repeated attempt, the number of reattempts, or suicide death within a period of time. The development of both passive and active collection of patients' data provides the opportunity to improve clinician knowledge and thus determine risk factors and relevant combinations of risk factors [11].

\section{Aims}

This study aims to combine data from EHRs to provide support to decision making for clinicians in suicide prevention. We present the main results of a data mining process on a sample of suicide attempters to first identify groups of similar patients and then identify risk factors associated with the number of suicide attempts. We hypothesize that a data mining process helps to better characterize the population of suicide attempters by identifying the most relevant groups of patients and their associated risk factors for suicide reattempt (or other variables of interest). The ultimate goal is to build a CDSS for clinician decision support and propose a personalized prevention and intervention strategy to each patient.

\section{Methods}

\section{Patient Recruitment}

Suicide attempters aged $>18$ years were recruited from consecutive admissions to the Emergency Department or specialized Acute Care Unit of three university hospitals (University Hospital Ramon y Cajal, Madrid, Spain; Fundación Jimenez Diaz, Madrid, Spain; and Academic Hospital of Montpellier, Montpellier, France) between 1994 and 2006. Owing to their specific characteristics $[12,13]$, major suicide repeaters were excluded. One of the hospitals is part of the Spanish National Health System and the other, the French National Health System; both hospitals provide medical coverage for all emergencies in a catchment area covering a population of around 500,000 people in Madrid and 400,000 in Montpellier. After providing a complete description of the study to participants, written informed consent was obtained. Trained psychiatrists or psychologists interviewed all patients before discharge. The study was approved by the local research ethics committees in Madrid and Montpellier (CPP Montpellier Sud-Méditerranée IV, CHU Montpellier). The research followed the Code of Ethics of the World Medical Association (Declaration of Helsinki). Protocols and assessment procedures in both centers are based on the Columbia Suicide History Form [14].

\section{Procedure and Clinical Assessment}

The French or Spanish version of the Mini-International Neuropsychiatric Interview (MINI) [15] was used to obtain Axis I Diagnostic and Statistical Manual of Mental Disorders - 4th edition diagnoses. Psychiatric diagnoses were classified in the following categories: mood disorder (specifying depression or bipolar disorder), anxiety disorders, obsessive-compulsive disorder, alcohol or drug misuse, psychotic disorders, eating disorders, somatoform disorders, and adjustment disorders. The lifetime diagnosis was determined using a best-estimate procedure. The psychiatrist in charge of the patient's care assigned the diagnosis based on MINI interviews, medical records, and information from relatives, when available. 
Suicide risk was assessed using the Suicide Intent Scale [16], a semistructured 15 -item rating scale yielding a global score that indicates the severity of suicidal intent. The Risk-Rescue Rating Scale [17] is a 10-item interviewer-administered scale designed to assess the lethality and intent of a suicide attempt, measuring the life risk derived from it, and the likelihood of a rescue intervention at the time of the attempt.

\section{Statistical Methods}

A robust data-qualification process was performed to ensure data quality and consistency before statistical analyses. Although data were intended to be collected according to the same clinical procedures, quality variations were expected between the hospitals. Missing data were identified, and a variable was retained only when the completion rate reached $70 \%$. When needed, new variables were created. For instance, 34 answers of the Barratt Impulsiveness Scale survey, version 10 (BIS10), were treated to build 3 scores of impulsiveness in terms of motor impulsivity, attentional impulsivity, or nonplanning impulsivity [18]. For each question of the BIS10, the score ranged from 1 (low impulsivity) to 4 (high impulsivity). The total score ranges from 34 to 136 points. The subscores ranged from 11 to 44 points for motor and attentional impulsivity and from 12 to 48 points for nonplanning impulsivity.

Unidimensional and two-dimensional analyses for both quantitative and qualitative variables were carried out. In addition, Fisher-Snedecor procedures were used to compare the two subgroups (male vs female) when needed. An unsupervised approach was used to extract homogeneous patterns from the data without any prior hypothesis. The approach is based on a multiple correspondence analysis (MCA) of qualitative variables to reduce the dimensionality. It consists of representing patients in a factorial space where each dimension is a combination of initial variables. Quantitative variables (eg, age) are not used during the calculations but are projected onto the factorial space. Hierarchical Clustering on Principal Components is then performed from the patients' representation in the initial factorial space. Hierarchical clustering has many advantages, including the construction of a hierarchical tree called dendrogram that enables a visual interpretation of the dataset. The dendrogram depicts the emergence of groups of patients who share common risk patterns. In addition, it facilitates discussion between statisticians and practitioners to choose the optimal number of clusters. Each cluster was then interpreted through the association between the cluster and the list of qualitative and quantitative variables (V test). In the second step, the focus was on the variable of interest-the number of suicide attempts. Recursive partitioning has been used as a multivariable procedure that classifies individuals (patients) by successively splitting into subpopulations. Furthermore, a regression tree was built, and the number of suicide attempts was explained by different binary tests on predictive variables.

\section{Results}

\section{Population Description}

From the original database, the first step relied on data qualification. Several redundancies (eg, duplicated surveys or alternative coding) were observed among 263 initial variables. Subsequently, a completion threshold was applied to the resulting variables, and only 23 variables satisfied a $70 \%$ minimum completion rate. Three additional variables related to the types of impulsivity (as described above) were added. With respect to the 2802 initial patients, we decided to keep only suicide attempters with a $100 \%$ completion rate for the 26 variables. In the final filtering, 5 variables were disregarded for redundancy or useless purpose (the type of patients, assessment date, source, and year and day of birth). This rigorous process ensured high data quality for both patients and variables; it also provided a final dataset of 681 patients and 21 variables. Participants were predominantly young (mean age 40.1 years), female, employed, and married. Most patients included in the final analysis had a history of mental disorders, including major depression (482/681, 70.8\%), bipolar disorder (160/681, 23.0\%), dysthymic disorder $(30 / 681,4.4 \%)$, obsessive-compulsive disorder (58/681, 8.5\%), and alcohol misuse (178/681, 26.1\%) (Table 1). 
Table 1. Clinicosociological main features of the postfiltering dataset of 681 suicide attempters.

\begin{tabular}{|c|c|}
\hline Features & Value \\
\hline \multicolumn{2}{|l|}{ General features } \\
\hline \multicolumn{2}{|l|}{ Qualitative variables, n (\%) } \\
\hline \multicolumn{2}{|l|}{ Sex } \\
\hline Female & $493(72.4)$ \\
\hline Male & $188(27.6)$ \\
\hline \multicolumn{2}{|l|}{ Marital status } \\
\hline Single & $239(35.1)$ \\
\hline Married & $240(35.2)$ \\
\hline Separated or divorced & $181(26.6)$ \\
\hline Widowed & $21(3.1)$ \\
\hline \multicolumn{2}{|l|}{ Children } \\
\hline No & $272(39.9)$ \\
\hline Yes & $409(60.1)$ \\
\hline \multicolumn{2}{|l|}{ Education } \\
\hline Low & $31(4.6)$ \\
\hline Intermediate & $368(54.0)$ \\
\hline High & $282(41.4)$ \\
\hline \multicolumn{2}{|l|}{ Employment } \\
\hline Employed & $451(66.2)$ \\
\hline Unemployed & $110(16.2)$ \\
\hline Incapacity & $41(6.0)$ \\
\hline Retired & $79(11.6)$ \\
\hline Quantitative variable, age (years), median (Q1-Q3) & $40.6(28-49.6)$ \\
\hline \multicolumn{2}{|l|}{ Clinical features } \\
\hline \multicolumn{2}{|l|}{ Qualitative variables, n (\%) } \\
\hline \multicolumn{2}{|l|}{ History of mental disorder } \\
\hline No & $6(0.9)$ \\
\hline Yes & $675(99.1)$ \\
\hline \multicolumn{2}{|l|}{ History of family suicidal behavior } \\
\hline No & $424(62.3)$ \\
\hline Yes & $257(37.7)$ \\
\hline \multicolumn{2}{|l|}{ Lifetime major depression } \\
\hline No & $199(29.2)$ \\
\hline Yes & $482(70.8)$ \\
\hline \multicolumn{2}{|l|}{ Lifetime bipolar disorder } \\
\hline No & $521(76.5)$ \\
\hline Yes & $160(23.5)$ \\
\hline \multicolumn{2}{|l|}{ Lifetime dysthymic disorder } \\
\hline No & $651(95.6)$ \\
\hline Yes & $30(4.4)$ \\
\hline \multicolumn{2}{|l|}{ Lifetime obsessive-compulsive disorder } \\
\hline No & $623(91.5)$ \\
\hline
\end{tabular}




\begin{tabular}{|c|c|}
\hline Features & Value \\
\hline Yes & $58(8.5)$ \\
\hline \multicolumn{2}{|l|}{ Lifetime eating disorder } \\
\hline No & $571(83.8)$ \\
\hline Yes & $110(16.2)$ \\
\hline \multicolumn{2}{|l|}{ Lifetime alcohol-drug misuse } \\
\hline No & $465(68.3)$ \\
\hline Yes & $216(31.7)$ \\
\hline \multicolumn{2}{|l|}{ Lifetime substance misuse } \\
\hline No & $586(86.0)$ \\
\hline Yes & $95(14.0)$ \\
\hline \multicolumn{2}{|l|}{ Lifetime alcohol abuse } \\
\hline No & $503(73.9)$ \\
\hline Yes & $178(26.1)$ \\
\hline \multicolumn{2}{|l|}{ Quantitative variable } \\
\hline Number of suicide attempts, median (Q1-Q3) & $2(1-3)$ \\
\hline \multicolumn{2}{|c|}{ Barratt Impulsiveness Scale survey - version 10, scores (range) } \\
\hline Motor impulsivity & $26(22-30)$ \\
\hline Attentional impulsivity & $27(23-30)$ \\
\hline Nonplanning impulsivity & $28(24-31)$ \\
\hline
\end{tabular}

\section{Principal Outcome: Clustering of Patients}

The first step of the analysis was to perform an MCA to reduce the dimension, followed by a hierarchical clustering from the principal components to highlight groups of homogeneous patients. The tree structure (in terms of inertia gain) and a discussion between statisticians and practitioners allowed us to study patients partitioned into three clusters. Figure 1 shows the cluster dendrogram and the projection of the three clusters onto the factor map; the factor map represents a two-dimensional projection of the first two dimensions only.

We conducted an in-depth analysis of the 3 groups for data interpretation. Statistical association tests (V tests) enabled identification of over- or underrepresented modalities in the three clusters. Cluster 1 was mainly related to an average patient profile of women (positive association $\mathrm{V}$ test, $P<.001$ ) who did not misuse drugs, substances, or alcohol $(P<.001)$ and without bipolar disorder $(P<.001)$, but with previous or current episodes of depression $(P<.001)$ and other mental health disorders $(P=.01)$. Cluster 3 was, in contrast, associated with men $(P<.001)$ and drug, substance, and alcohol misuse $(P<.001)$; in this group, patients were mainly single $(P=.01)$, with no children $(P=.006)$ and no experience of depression $(P=.006)$. Compared with clusters 1 and 3, cluster 2 was neutral in terms of gender, but this group was related to people with a work incapacity $(P=.03)$, low education level $(P=.02)$, possible bipolar disorder $(P<.001)$, and no drugs or alcohol misuse $(P<.001)$ and without episodes of depression or other mental health disorders $(P<.001)$. Thus, without any prior hypothesis, this unsupervised approach underlined three homogeneous groups. Gender appeared as a crucial marker for two of the three groups. 
Figure 1. Hierarchical clustering (left) and multiple correspondence analysis factor map (right) with three projected clusters.
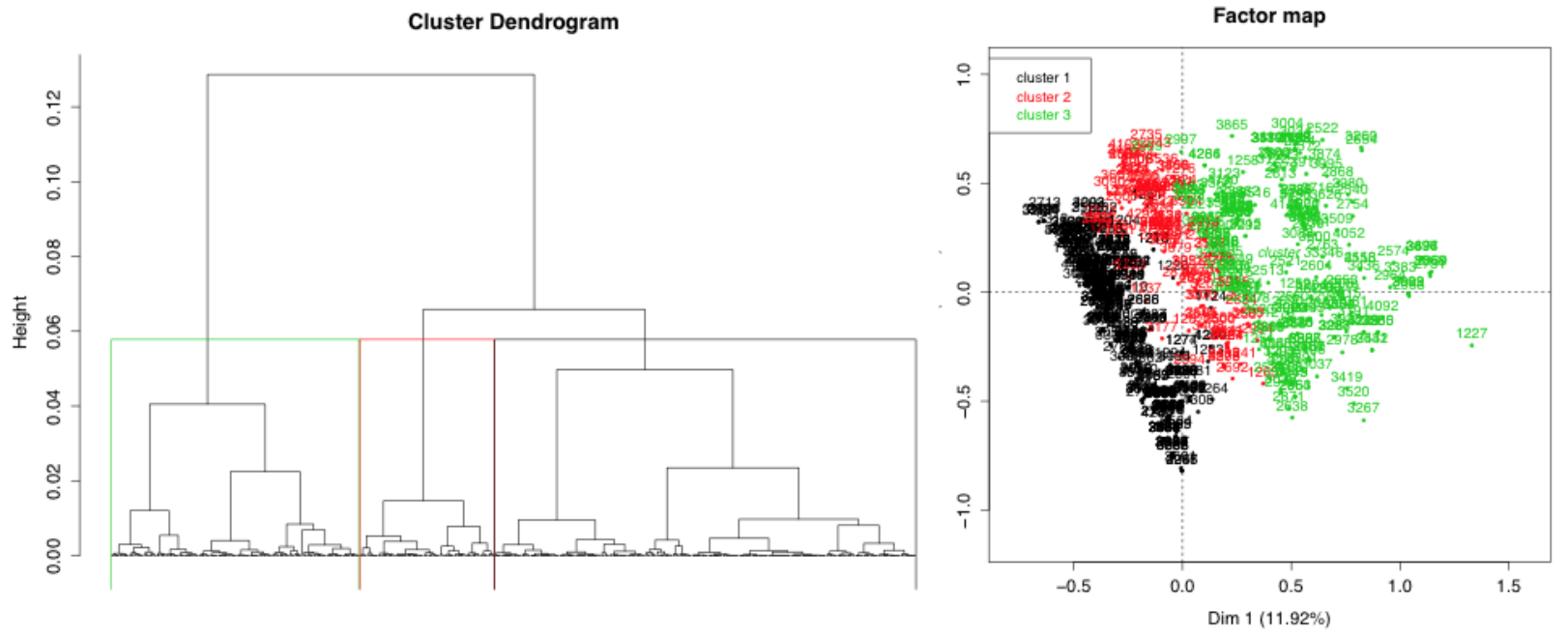

\section{Secondary Outcome: Identification of Factors Associated With the Risk of Repeated Suicide Attempts}

The second step of the analysis aimed to identify factors associated with a higher risk of suicide attempts (variable "number of suicide attempts") for men and women separately, following the principal outcome. Figure 2 depicts the regression tree for male patients, while Figure 3 shows the results for female patients only. For both groups, we noted that impulsivity aspects (including the motor section, nonplanning section, and attentional impulsivity section of the BIS interview) were relevant factors explaining the number of suicide attempts for a patient. Furthermore, higher scores were associated with a higher number of attempts for patients.

While analyzing both groups, the first conclusion is a clear difference between genders. For instance, eating disorders are linked to a higher number of suicide attempts for women (mean 2.9 in women vs 2.3 in men, $P=.005$ ), while a history of familial suicidal behavior (mean 2.8 in men vs 1.7 in women, $P<.001$ ) and the employment status are risk factors for some men. In particular, unemployed men with higher scores at the BIS interview were at higher risk of suicide repetition. Older age and having children were also identified as risks factors.

Figure 2. The decision tree on the variable "number of suicide attempts" according to gender "male". BIS: Barratt Impulsiveness Scale.

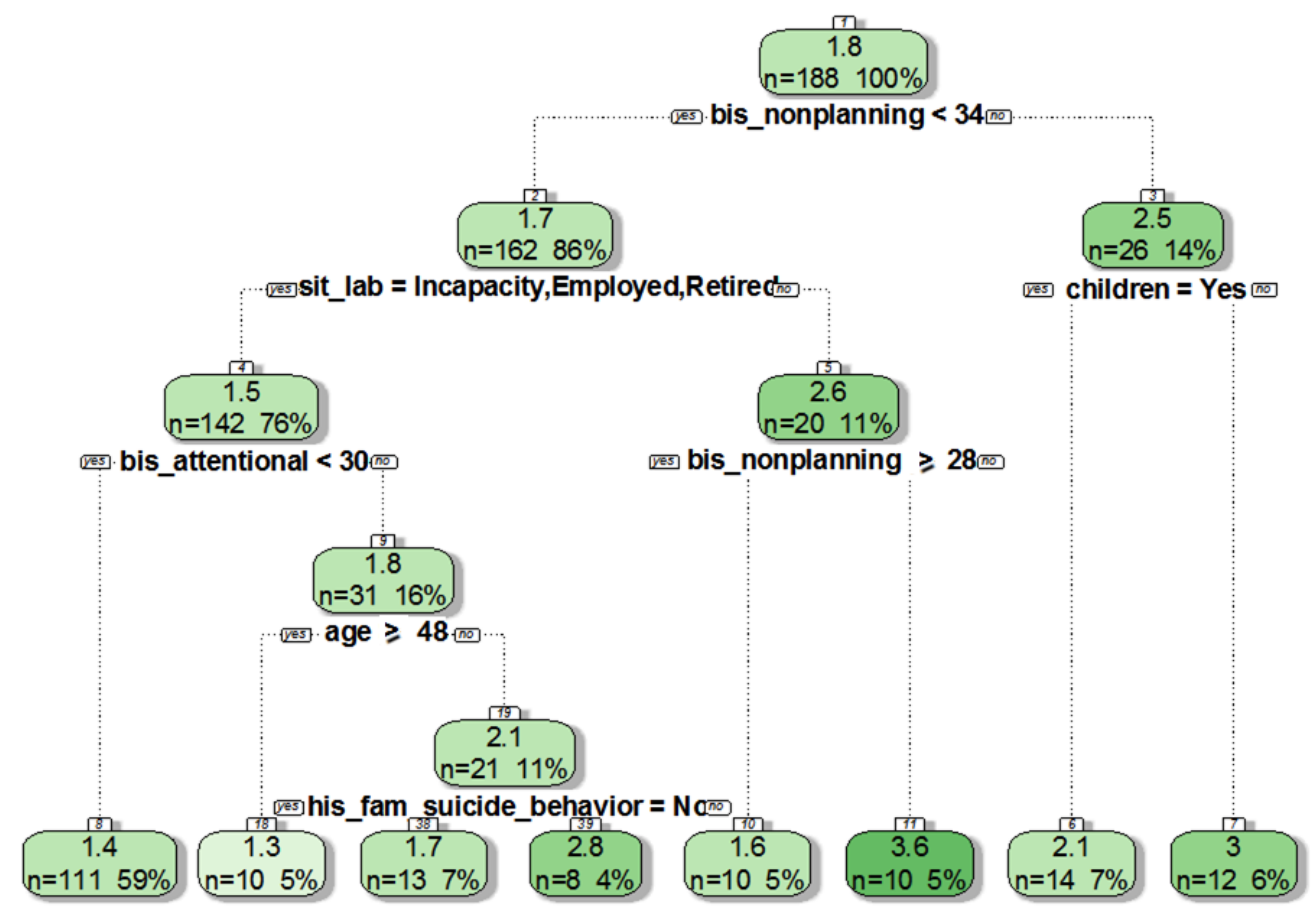


Figure 3. The decision tree on the variable "number of suicide attempts" according to gender "female". BIS: Barratt Impulsiveness Scale.

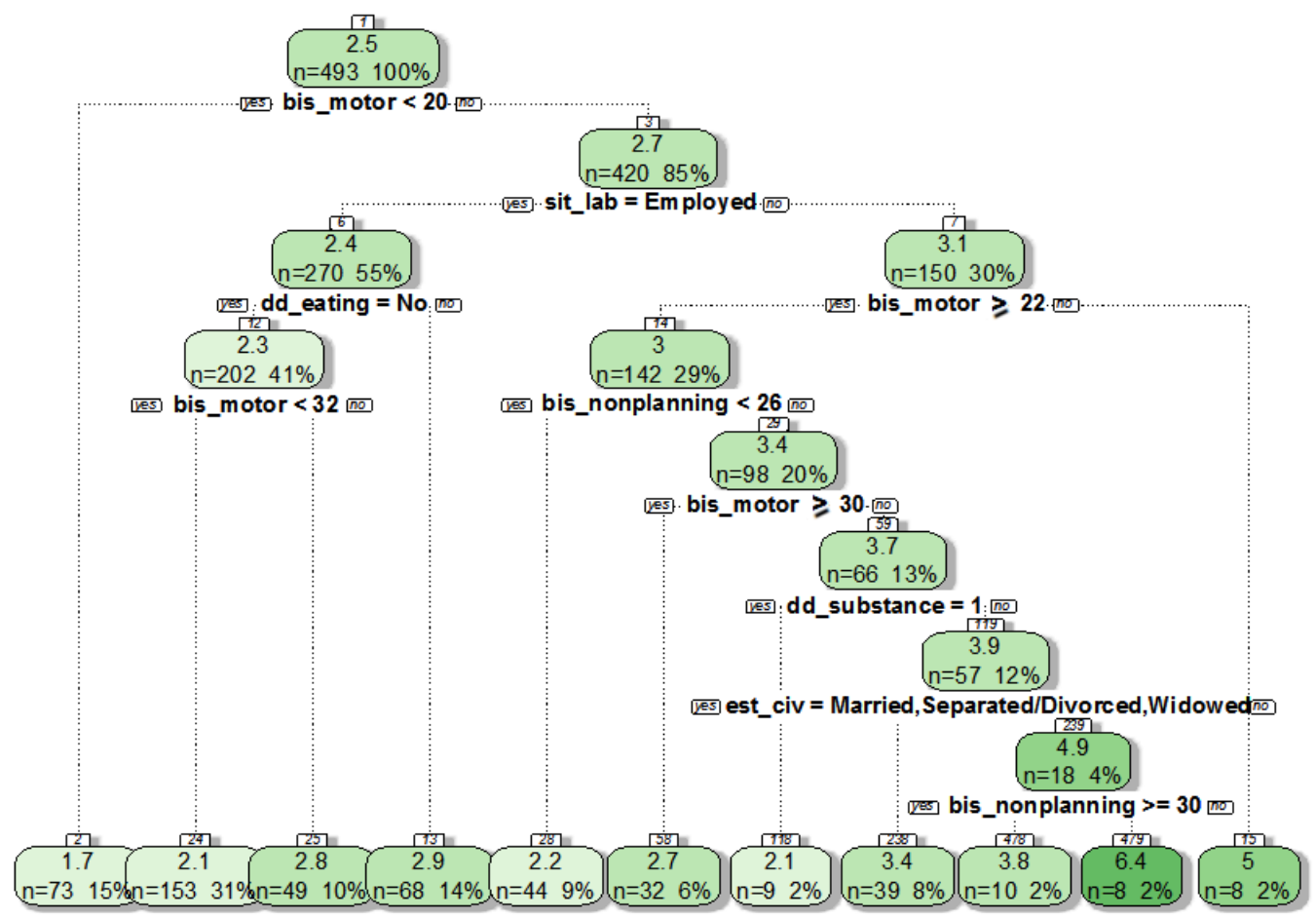

\section{Discussion}

\section{Principal Findings and Integration into a Dynamic Clinical Decision-Support System}

A systematic assessment before discharge from hospital has allowed building of a large database suitable for modern data mining techniques. In this study, we identified clusters of suicide attempters and variables that may explain the repetition of suicide attempt in suicide attempters. This study shows how a simple structuration of the assessment of discharged patients after a suicide attempt may provide relevant data for clustering methods. The clustering may help clinicians allocate a patient into a risk cluster. Therefore, it is the first step of the CDSS design. This model may lead to a stratified approach in decision making for suicide prevention. Furthermore, analyzing larger datasets could allow the discovery of new risk factors that are not currently considered relevant during clinical interviews. However, we did not propose a model for suicide prediction; our model mining big databases is a prerequisite toward better decision making for suicide prevention. Furthermore, this model could also be applied to other data sources like personal health records or ecological momentary assessment (EMA).

Our findings are in line with recent studies showing how suicide risk assessment could lead to patient clustering from a preventative perspective [19]. Eleven clinically relevant items related to the characteristics of suicidal behavior were submitted to a Hierarchical Ascendant Classification; the results showed that most individuals were included in a cluster characterized by less lethal means and planning ("impulse-ambivalent"). The second cluster featured more carefully planned attempts ("well-planned"), more alcohol or drug use before the attempt, and more precautions to avoid interruptions. Finally, the third cluster included individuals reporting more attempts ("frequent"), more often serious or violent attempts, and an earlier age at the first attempt. In addition, differences across clusters by demographic and clinical characteristics were found, particularly with the third cluster whose participants had experienced high levels of childhood abuse. Overall, a systematic, structured assessment may help clinicians characterize suicide risk better and personalize prevention strategies. We believe that electronic health and data mining techniques may help us to reach this goal.

In this study, participants were assessed by trained clinicians before discharge from the ED. Data were captured using paper-based formularies of the actual MeMind Web-based EHR [20]; these data could have been captured by our MeMind Web app [20] designed to gather observational data through an EHR interface and perform EMA [18,19]. This Web-based software has two distinct views-the EHR view (for clinicians) and the EMA view (for patients). The "EHR" view is designed to be used by doctors and nurses during the face-to-face assessment. As current EHRs, the app also collects sociodemographic, diagnostic, and pharmacological treatment information within the "assessing suicide" protocol. Sociodemographic variables included age (defined as the age at the index episode), sex, profession, current working status, marital status, number of children (if any), and educational level. Moreover, family history of suicidal behavior, age at the first suicide attempt, and violence of the suicide attempt were measured. The EMA view for patients to track their symptoms was not used in this study. Clinicians and patients can access the Web app either from a computer or their personal mobile phone. EMA involves repeated sampling of subjects' behaviors and experiences in real time in their natural environment. EMA has been successfully used for real-time self-reporting of symptoms and behavior. For example, Husky et al showed the utility and 
feasibility of using EMA to study suicidal ideation [4]. For this study, patients did not have any access to this interface. Such a Web app may represent the future of suicide risk assessment, as it allows data mining of static data (EHR data provided by a single clinical assessment) and dynamic data (smartphone data provided by EMA techniques); these data can be processed to build a dynamic CDSS [19].

\section{Limitations}

\section{Focus on Suicide Attempters}

In this study, patients were recruited after a suicide attempt. We postulate that the development of a CDSS would be more relevant in a population of suicide attempters. Suicide attempters are also defined as an "indicated population" [2] who warrant the maximal attention of health care service owing to the risk of reattempt. Treatment and follow-up strategies are well described in the guidelines for suicide attempters. Therefore, we were able to propose treatment to each participant based on actual recommendations. However, applying these strategies to samples of patients with suicide ideation but without a history of suicide attempt would be hypothetical and ethically controversial. Owing to the epidemiological specificities of both populations, a specific model would have to be built for each population. In terms of multiple suicide attempters, a relevant perspective is to focus on the temporality of suicide attempts rather than the absolute number; to achieve this objective, finer data are needed.

\section{Missing Data: The Data Mining Challenge}

This study illustrates the need for high-quality and large databases for extracting significant patient profiles or risk factors. In this study, starting from an initial set of 2802 patients with 263 variables, the data-qualification process resulted in a final sample of 681 patients with 21 complete variables. Although this volume of data already ensures statistical significance, it underlines the importance of better ways to standardize data collection in participating institutions. The CDSS quality strongly depends on input data. Moreover, a critical challenge may be the clinician acceptance of such tools that directly impact the completion rate of the EHR [21]. Another option could be the integration of other data sources, such as personal health records and EMA [21]. Overall, the use of larger databases will refine different profiles of patients and dynamically improve the personalized prevention strategies, thanks to the EMA data.

\section{Recommendations for Suicide Prevention}

\section{From Guidelines to Clinical Decision-Support Systems in Suicide Prevention}

Guidelines recommend that all patients presenting to the hospital services with self-harm should receive a psychological assessment before discharge, to determine the risk of further reattempt [6]. This assessment should also help clinicians choose the most appropriate treatment while considering clinical guidelines and patient-specific risks factor. However, reviews have addressed the challenge clinicians working in the emergency setting face when they rely on these tools to perform decision making [7]. As EHRs are extensively used in emergency services and psychiatric departments, we propose integrating CDSS features regarding an individual's risks factors into EHRs.

\section{Toward Dynamic Clinical Decision-Support Systems}

Most clinicians have use EHRs daily in emergency services and psychiatric units. However, few institutions have taken advantage of recent technological advances opportunities in risk assessment. Combining electronic health-based assessment with data mining techniques represents an opportunity to foster suicide-prevention research. This new paradigm is useful in providing personalized intervention strategies by itself, but it also affords the opportunity to identify novel mechanisms to be targeted in suicide-prevention strategies. In addition, we believe that computational models can provide data-assisted ideas emerging from these repositories and will have special appeal for the empirically minded clinicians [7].

Although studies have highlighted the value of self-reports in clinical assessment, they are rarely routinely implemented [22]. Internet and mobile technologies are ideal for self-monitoring assessment and ecological observational studies. Mobile phones are generally kept on at all times and carried everywhere, making them an ideal platform for the broad implementation of EMA technology. For example, Husky et al conducted a study providing support for the use of EMA in the identification of suicidal ideation in outpatients [23]. These techniques may help clinicians identify risky events occurring during follow-up. Overall, these EMA data could also be mined and integrated into the decision-making process.

\section{Conclusions}

The next step is to take advantage of new technologies and current developments of Web-based mobile apps to design the next-generation dynamic CDSS (Figure 4). As emerging mobile health (mHealth) techniques in suicide prevention strategies also produce relevant data, this study proposes a new model of the decision-support system based on the data mining proceedings from face-to-face assessment and mHealth EMA. Our strategy relies on the processing of static data (initial assessment) and dynamic data (EMA) able to instantaneously deliver to clinicians decision support regarding a specific patient. Indeed, mHealth apps allow patients to report their physical or mental health conditions and symptoms, hence providing dynamic data able to enrich studies, confirming or rejecting statistical hypotheses [24]. Such dynamic data based on EMA will form the core of a dynamic decision-support system, which will adapt its recommendations to patients' characteristics (Figure 4). 
Figure 4. The decision-support system based on ecological momentary assessment and data mining.

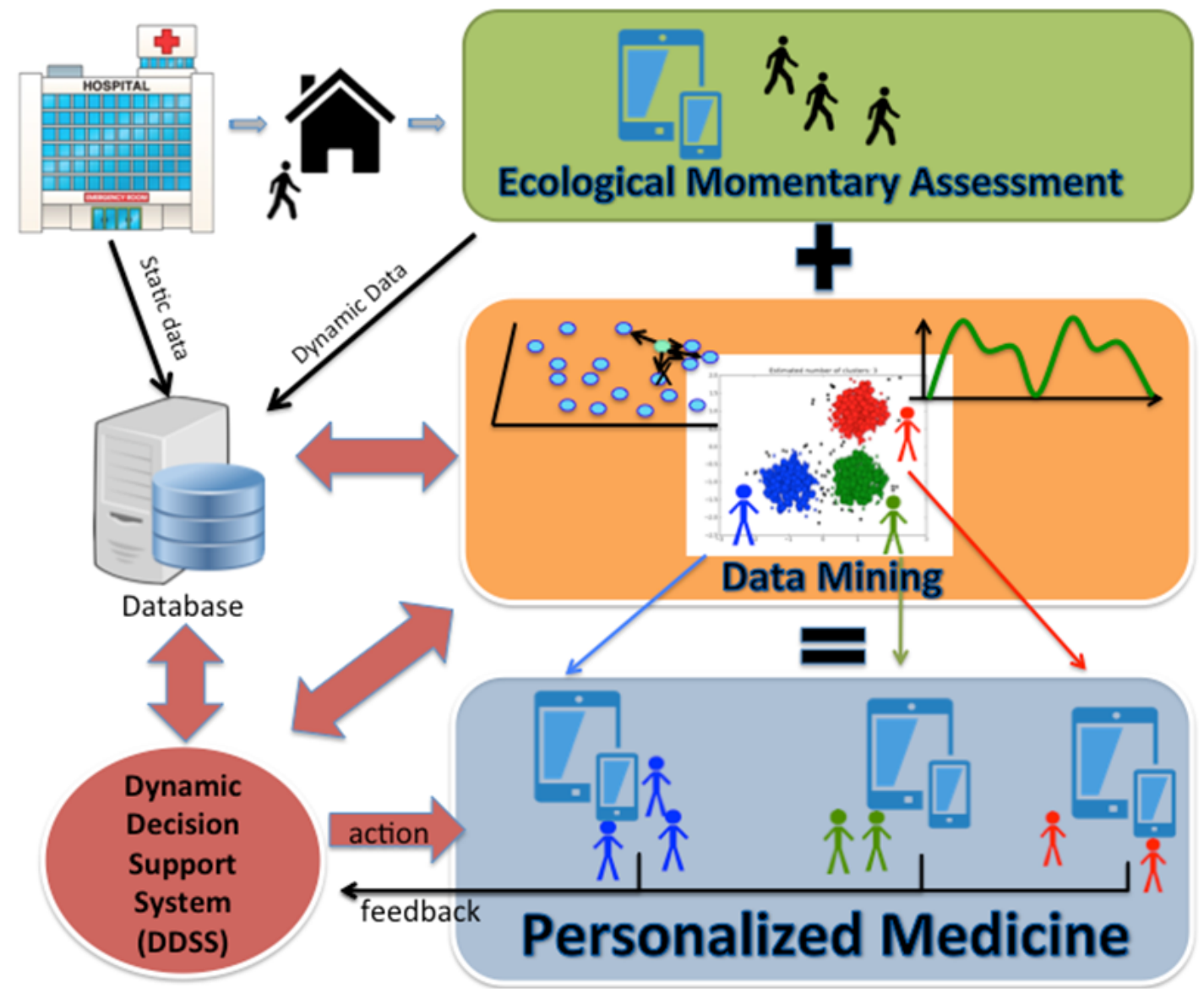

\section{Acknowledgments}

Authors acknowledge the French Groupement d'Etude et de Prevention du Suicide (GEPS) and the French Embassy in Madrid, Spain. This study received a Hospital Clinical Research Grant (PHRC 2009) from the French Health Ministry. None of the funding sources had any involvement in the study design; collection, analysis, or interpretation of data; writing of the report; or the decision to submit the paper for publication. This study was funded partially by Instituto de Salud Carlos III (ISCIII PI13/02200; PI16/01852), Delegación del Gobierno para el Plan Nacional de Drogas (20151073), and the American Foundation for Suicide Prevention (LSRG-1-005-16).

\section{Conflicts of Interest}

None declared.

\section{References}

1. Finkelstein Y, Macdonald EM, Hollands S, Sivilotti MLA, Hutson JR, Mamdani MM, Canadian Drug SafetyEffectiveness Research Network (CDSERN). Risk of Suicide Following Deliberate Self-poisoning. JAMA Psychiatry 2015 Jun;72(6):570-575. [doi: 10.1001/jamapsychiatry.2014.3188] [Medline: 25830811]

2. Zalsman G, Hawton K, Wasserman D, van Heeringen K, Arensman E, Sarchiapone M, et al. Suicide prevention strategies revisited: 10-year systematic review. Lancet Psychiatry 2016 Jul;3(7):646-659. [doi: 10.1016/S2215-0366(16)30030-X] [Medline: $\underline{27289303}$ ]

3. Chiu HY, Lee HC, Chen PY, Lai YF, Tu YK. Associations between sleep duration and suicidality in adolescents: A systematic review and dose-response meta-analysis. Sleep Med Rev 2018 Dec;42:119-126. [doi: 10.1016/j.smrv.2018.07.003] [Medline: 30093362]

4. Husky M, Swendsen J, Ionita A, Jaussent I, Genty C, Courtet P. Predictors of daily life suicidal ideation in adults recently discharged after a serious suicide attempt: A pilot study. Psychiatry Res 2017 Dec;256:79-84. [doi: 10.1016/j.psychres.2017.06.035] [Medline: 28624676] 
5. Berrouiguet S, Courtet P, Larsen ME, Walter M, Vaiva G. Suicide prevention: Towards integrative, innovative and individualized brief contact interventions. Eur Psychiatry 2018 Jan;47:25-26. [doi: 10.1016/j.eurpsy.2017.09.006] [Medline: 29096129]

6. Chan MKY, Bhatti H, Meader N, Stockton S, Evans J, O'Connor RC, et al. Predicting suicide following self-harm: systematic review of risk factors and risk scales. Br J Psychiatry 2016 Dec;209(4):277-283. [doi: 10.1192/bjp.bp.115.170050] [Medline: 27340111]

7. Mulder R, Newton-Howes G, Coid J. The futility of risk prediction in psychiatry. Br J Psychiatry 2016 Dec;209(4):271-272. [doi: 10.1192/bjp.bp.116.184960] [Medline: 27698212]

8. Kruse CS, Mileski M, Vijaykumar AG, Viswanathan SV, Suskandla U, Chidambaram Y. Impact of Electronic Health Records on Long-Term Care Facilities: Systematic Review. JMIR Med Inform 2017 Sep 29;5(3):e35 [FREE Full text] [doi: 10.2196/medinform.7958] [Medline: 28963091]

9. Celi LA, Zimolzak AJ, Stone DJ. Dynamic clinical data mining: search engine-based decision support. JMIR Med Inform 2014 Jun 23;2(1):e13 [FREE Full text] [doi: 10.2196/medinform.3110] [Medline: 25600664]

10. Karmakar C, Luo W, Tran T, Berk M, Venkatesh S. Predicting Risk of Suicide Attempt Using History of Physical Illnesses From Electronic Medical Records. JMIR Ment Health 2016 Jul 11;3(3):e19 [FREE Full text] [doi: 10.2196/mental.5475] [Medline: 27400764]

11. Glenn C, Nock M. Improving the short-term prediction of suicidal behavior. Am J Prev Med 2014 Sep;47(3 Suppl 2):S176-S180 [FREE Full text] [doi: 10.1016/j.amepre.2014.06.004] [Medline: 25145736]

12. Mendez-Bustos P, de Leon-Martinez V, Miret M, Baca-Garcia E, Lopez-Castroman J. Suicide reattempters: a systematic review. Harv Rev Psychiatry 2013;21(6):281-295. [doi: 10.1097/HRP.0000000000000001] [Medline: 24201820]

13. Blasco-Fontecilla H, Jaussent I, Olié E, Béziat S, Guillaume S, Artieda-Urrutia P, et al. A cross-sectional study of major repeaters: a distinct phenotype of suicidal behavior. Prim Care Companion CNS Disord 2014;16(4) [FREE Full text] [doi: 10.4088/PCC.14m01633] [Medline: 25664212]

14. Posner K, Brown GK, Stanley B, Brent DA, Yershova KV, Oquendo MA, et al. The Columbia-Suicide Severity Rating Scale: initial validity and internal consistency findings from three multisite studies with adolescents and adults. Am J Psychiatry 2011 Dec;168(12):1266-1277 [FREE Full text] [doi: 10.1176/appi.ajp.2011.10111704] [Medline: 22193671]

15. Sheehan DV, Lecrubier Y, Sheehan KH, Amorim P, Janavs J, Weiller E, et al. The Mini-International Neuropsychiatric Interview (M.I.N.I.): the development and validation of a structured diagnostic psychiatric interview for DSM-IV and ICD-10. J Clin Psychiatry 1998;59 Suppl 20:22-33;quiz 34 [FREE Full text] [Medline: 9881538]

16. Beck R, Morris J, Beck A. Cross-validation of the Suicidal Intent Scale. Psychol Rep 1974 Apr;34(2):445-446. [doi: 10.2466/pr0.1974.34.2.445] [Medline: 4820501$]$

17. Weisman A, Worden J. Risk-rescue rating in suicide assessment. Arch Gen Psychiatry 1972 Jun;26(6):553-560. [Medline: 5027119]

18. Patton J, Stanford M, Barratt E. Factor structure of the Barratt impulsiveness scale. J Clin Psychol 1995 Nov;51(6):768-774. [Medline: $\underline{8778124]}$

19. Berrouiguet S, Barrigón ML, Brandt SA, Nitzburg GC, Ovejero S, Alvarez-Garcia R, et al. Ecological Assessment of Clinicians' Antipsychotic Prescription Habits in Psychiatric Inpatients: A Novel Web- and Mobile Phone-Based Prototype for a Dynamic Clinical Decision Support System. J Med Internet Res 2017 Jan 26;19(1):e25 [FREE Full text] [doi: 10.2196/jmir.5954] [Medline: 28126703]

20. Memind. URL: https://www.memind.net/es/app/security/login/ [accessed 2019-02-28] [WebCite Cache ID 76X1AbIJZ]

21. Beglaryan M, Petrosyan V, Bunker E. Development of a tripolar model of technology acceptance: Hospital-based physicians' perspective on EHR. Int J Med Inform 2017 Dec;102:50-61. [doi: 10.1016/j.ijmedinf.2017.02.013] [Medline: 28495348]

22. Davidson CL, Anestis MD, Gutierrez PM. Ecological Momentary Assessment is a Neglected Methodology in Suicidology. Arch Suicide Res 2017 Jan 02;21(1):1-11. [doi: 10.1080/13811118.2015.1004482] [Medline: 26821811]

23. Husky M, Olié E, Guillaume S, Genty C, Swendsen J, Courtet P. Feasibility and validity of ecological momentary assessment in the investigation of suicide risk. Psychiatry Res 2014 Dec 15;220(1-2):564-570. [doi: 10.1016/j.psychres.2014.08.019] [Medline: 25155939]

24. Larsen ME, Nicholas J, Christensen H. A Systematic Assessment of Smartphone Tools for Suicide Prevention. PLoS One 2016;11(4):e0152285 [FREE Full text] [doi: 10.1371/journal.pone.0152285] [Medline: 27073900]

\section{Abbreviations}

CDSS: clinical decision-support system

EHR: electronic health records

EMA: ecological momentary assessment

MCA: multiple correspondence analysis

mHealth: mobile health

MINI: Mini-International Neuropsychiatric Interview 
Edited by $G$ Wadley, $R$ Calvo, M Czerwinski, J Torous; submitted 10.02.18; peer-reviewed by P Winkler, K Krysinska, A Kotlo; comments to author 08.03.18; revised version received 30.06.18; accepted 26.07.18; published 07.05.19

Please cite as:

Berrouiguet S, Billot R, Larsen ME, Lopez-Castroman J, Jaussent I, Walter M, Lenca P, Baca-García E, Courtet P

An Approach for Data Mining of Electronic Health Record Data for Suicide Risk Management: Database Analysis for Clinical Decision Support

JMIR Ment Health 2019;6(5):e9766

URL: https://mental.jmir.org/2019/5/e9766/

doi: 10.2196/mental.9766

PMID: 31066693

(C) Sofian Berrouiguet, Romain Billot, Mark Erik Larsen, Jorge Lopez-Castroman, Isabelle Jaussent, Michel Walter, Philippe Lenca, Enrique Baca-García, Philippe Courtet. Originally published in JMIR Mental Health (http://mental.jmir.org), 07.05.2019. This is an open-access article distributed under the terms of the Creative Commons Attribution License (https://creativecommons.org/licenses/by/4.0/), which permits unrestricted use, distribution, and reproduction in any medium, provided the original work, first published in JMIR Mental Health, is properly cited. The complete bibliographic information, a link to the original publication on http://mental.jmir.org/, as well as this copyright and license information must be included. 